\title{
Dr Langdon Down (1828-1896) and 'mongolism'
}

\author{
P M Dunn
}

John Langdon Down was born at Torpoint in Cornwall in 1828. After local schooling he became apprenticed at the age of 14 for four years to his father, a local apothecary. Then, wishing to become a scientist, in 1846 he entered a laboratory of the Pharmaceutical Society in London. There he won a prize for organic chemistry and also came into contact with Michael Faraday. In 1853 his father died and he decided to take up medicine, entering the London Hospital at the age of 25 and qualifying five years later with many honours and prizes including the gold medal for physiology. In 1858 he was appointed Medical Superintendent of the Earlswood Asylum for Idiots at Redhill in Surrey, a position he retained for 10 years before establishing his own institution for mentally retarded children, Normansfield, at Teddington. Within a year of qualifying he had obtained both the MRCP and MD, and had been elected to the staff of the London Hospital as a physician. There he taught therapeutics and medicine, and his humanity and care for the mentally retarded brought him a large private practice. Down did not write a great deal but is eponymously remembered for his classic description of mongolism in a short essay in $1866,{ }^{1}$ from which the following extracts are taken:

'The medical practitioner who may be consulted in any given case, has, perhaps in a very early condition of the child's life, to give an opinion on points of vital importance as to the present condition and probable future of the little one. Moreover, he may be pressed as to the question, whether the supposed defect dates from any cause subsequent to the birth or not. Has the nurse dosed the child with opium? Has the little one met with any accident? Has the instrumental interference which maternal safety demanded, been the cause of what seems to the anxious parents, a vacant future? Can it be that when away from the family attendant the calomel powders were judiciously prescribed? Can, in fact, the strange anomalies which the child presents, be attributed to the numerous causes which maternal solicitude conjures to the imagination, in order to account for a condition, for which any cause is sought, rather than hereditary taint or parental influence.

University of Bristol, Southmead Hospital

Correspondence to: Professor P M Dunn, Department of Child Health, Southmead Hospital, Southmead Road, Bristol BS10 5NB.
I have for some time had my attention directed to the possibility of making a classification of the feeble-minded, by arranging them around various ethnic standards . . .'

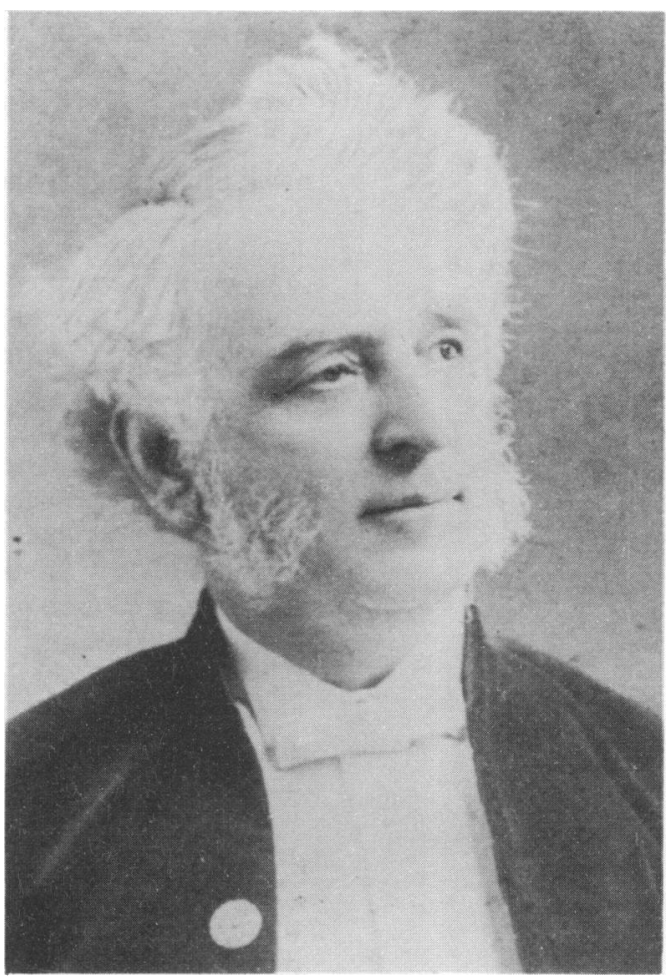

Dr Fohn Langdon Down (1828-96).

'The great Mongolian family has numerous representatives, and it is to this division, I wish, in this paper, to call special attention. A very large number of congenital idiots are typical Mongols. So marked is this, that when placed side by side, it is difficult to believe that the specimens compared are not children of the same parents. The number of idiots who arrange themselves around the Mongolian type is so great, and they present such a close resemblance to one another in mental power, that I shall describe an idiot member of this racial division, selected from the large number that have fallen under my observation.

The hair is not black, as in the real Mongol, but of a brownish colour, straight and scanty. The face is flat and broad, and destitute of prominence. The cheeks are roundish, and extended laterally. The eyes are obliquely placed, and the internal canthi more than normally distant from one another. The palpebral fissure is very narrow. The forehead is wrinkled transversely from the constant assistance which the levatores palpebrarum derive from the occipitofrontalis muscle in the opening of the eyes. The 
lips are large and thick with transverse fissures. The tongue is long, thick, and is much roughened. The nose is small. The skin has a slight dirty yellowish tinge, and is deficient in elasticity, giving the appearance of being too large for the body.

The boy's aspect is such that it is difficult to realize that he is the child of Europeans, but so frequently are these characters presented, that there can be no doubt that these ethnic features are the result of degeneration.

The Mongolian type of idiocy occurs in more than ten per cent of the cases which are presented to me. They are always congenital idiots, and never result from accidents after uterine life. They are, for the most part, instances of degeneracy arising from tuberculosis in the parents. They are cases which very much repay judicious treatment. They require highly azotised food with a considerable amount of oleaginous material. They have considerable power of imitation, even bordering on being mimics. They are humorous, and a lively sense of the ridiculous often colours their mimicry. This faculty of imitation may be cultivated to a very great extent, and a practical direction given to the results obtained. They are usually able to speak; the speech is thick and indistinct, but may be improved very greatly by a well-directed scheme of tongue gymnastics. The co-ordinating faculty is abnormal, but not so defective that it cannot be greatly strengthened. By systematic training, considerable manipulative power may be obtained.

The circulation is feeble, and whatever advance is made intellectually in the summer, some amount of retrogression may be expected in the winter. Their mental and physical capabilities are, in fact, directly as the temperature.

The improvement which training effects in them is greatly in excess of what would be predicted if one did not know the characteristics of the type. The life expectancy, however, is far below the average, and the tendency is to the tuberculosis, which I believe to be the hereditary origin of the degeneracy.

Apart from the practical bearing of this attempt at an ethnic classification, considerable philosophical interest attaches to it. The tendency in the present day is to reject the opinion that the various races are merely varieties of the human family having a common origin, and to insist that climatic, or other influences, are insufficient to account for the different types of man. Here, however, we have examples of retrogression, or at all events, of departure from one type and the assumption of the characteristics of another. If these great racial divisions are fixed and definite, how comes it that disease is able to break down the barrier, and to simulate so closely the features of the members of another division. I cannot but think that the observations which I have recorded, are indica- tions that the differences in the races are not specific but variable.

These examples of the results of degeneracy among mankind, appear to me to furnish some arguments in favour of the unity of the human species.'

As Lord Brain pointed out, Down's ethnic classification of idiots led him to maintain that if a mentally defective member of a white race could show the racial features of a non-white race, it proved that racial differences were not specific. ${ }^{2}$ He used this argument to refute the apologists for Negro slavery in the southern states at the time of the American Civil War and to support the concept of the unity of mankind.

Langdon Down was a large handsome man with a charming manner and liberal views. He was an advocate of higher education for women and strongly disagreed with the view, current at that time, that this would make them liable to produce feeble-minded offspring. He enjoyed entertaining and become an alderman of the Middlesex County Council. He married and had two sons, both of whom became doctors and continued his work at Normansfield after his death there at the age of 68 in 1896. Indeed, his elder son Reginald, also studied mongolian defectives, including their palmar lines, and subsequently corrected his father's interpretation of this syndrome in $1906^{3}$ :

'It would appear that the characteristics which at first sight strikingly suggest Mongolian features and build are accidental and superficial, being constantly associates, as they are, with other features which are in no way characteristic of that race, and if this is a case of reversion it must be reversion to a type even further back than the Mongol stock, from which some ethnologists believe all the various races of men have sprung.

On the other hand, it may be an instance of "variation" though there seems to be a difficulty in applying such a term to a condition comprising so many widely different correlated peculiarities and recurring with such frequency.'

In 1959 Lejeune showed that mongolism was due to trisomy 21. A few years later representatives of the Mongolian People's Republic complained to the World Health Organisation that the use of the term Mongol to describe these defective children was objectionable. Their request that the term be abandoned was accepted and since that time the eponym Down's syndrome has been used.

1 Down JL. Observations on a ethnic classification of idiots London Hospital Reports 1866;3:259-62.

2 Brain, Lord. Chairman's opening remarks: historical introduction. In: Wolstenholme GEW, Porter R, eds Mongolism. Boston: Little, Brown Co, 1967:1-5. (Cib Foundation Study Group No 25.)

3 Langdon-Down RL. Some observations on the mongolian type of imbecility. Fournal of Mental Science 1906;52 $189-90$. 